\title{
THE EFFECT OF A SPRAY WITH 4,6-DINITRO-O-CRESOL (DNOC) ON NITROGEN NUTRITION AND YIELD OF IVINTER RYE (SECALE CEREALE L.)
}

\author{
by J. BRUINSMA
}

Plant Physiological Research Centre, Wageningen, Holland

\section{INTRODUCTION}

Spraying a young crop of winter cereals with a herbicidal solution of a salt of 4,6-dinitro-o-cresol (DNOC) generally results in an increased yield as compared with the yield of an untreated crop. Since this yield increase also appears in experiments on weed-free plots it cannot be ascribed only to the suppression of weed competition ${ }^{16}$.

One of the tentative explanations of this effect of a DNOC-spray on yield is that the spray might act as a nitrogen application. The commonly used ammonium salt contains 19.5 per cent nitrogen, which gradually becomes available in the course of the weeks during which the compound is decomposed in the soil 2 . From this source, however, only about $1 \mathrm{~kg}$ of nitrogen per ha can be released. A far larger nitrogen mineralization can be expected to result from the toxic action of DNOC on soil micro-organisms. In addition, competition for nitrogen between the relatively unaffected plant and the reduced microflora and microfauna might be shifted in favour of the crop. No quantitative data are available with regard to this effect 2 .

In agreement with the hypothesis that DNOC affects yield by means of an extra nitrogen supply, it has been frequently observed in field experiments that sprayed plots afterwards look as if they had received more nitrogen: a heavier vegetation develops which remains longer green at ripening ${ }^{3} 4$ ?. Moreover, in one case the DNOC-enhanced yield per ear could be correlated with the increased nitrogen content per culm 4 . It was also observed that a late nitrogen manuring has an additional effect on yield on top of the DNOC effect 8 .

In testing the supposition that a DNOC spray influences yield by supplying 
extra nitrogen, Riepma 17 investigated whether or not such a spray could partially replace nitrogen fertilizing. $\mathrm{He}$, too, found a cumulative effect of the two treatments on yield. However, he did not reach nitrogen saturation, on the one hand, and, on the other hand, fertilized several weeks after spraying, so that the two treatments were not applied at the same stage of development of the crop.

The present paper describes two successive experiments in which the effects were investigated of a simultaneous treatment with DNOC and nitrogen on nitrogen uptake, growth and yield of winter rye.

\section{EXPERIMENTAL PART}

The two experiments were performed in 1959/60 and 1960/'61 on two parts of a former heath field, a high, dry and sandy soil. This poor soil was chosen to get a strong nitrogen effect. Petkus winter rye was sown with a row drill at $25 \mathrm{~cm}$, at a density of $100 \mathrm{~kg}$ per ha, in the 1959/'60 experiment in the first week of November and in the 1960/61 experiment about October 20. Before sowing, the field was treated with $500 \mathrm{~kg}$ of basic slag per ha, while in February a fertilization of $500 \mathrm{~kg} 40 \%$ potash per ha was given.

The experiments were laid out according to a split-plot design. Three strips were each divided into four equal parts, one of which was to be left without any nitrogen, the three others receiving increasing amounts of nitrogen. Each part was split into four plots, enabling the introduction of the following four spraying treatments: none, DNOC, urea with an equal amount of nitrogen as the DNOC-spray, and DNOC+urea.

In the 1959/60 experiment, on March 3 in the morning, with an overcast sky and hardly any wind, $4.00 \mathrm{~kg} 100 \%$ ammonium-DNOC (Vondelingenplaat N.V.) and $1.67 \mathrm{~kg} \mathrm{100 \%}$ urea (British Drug House) were sprayed in 6001 per ha. The same compounds were used in the 1960/'61 experiment, but in somewhat lower concentrations, viz $3.64 \mathrm{~kg} \mathrm{NH}_{4}-\mathrm{DNOC}$ and $1.52 \mathrm{~kg}$ urea in $630 \mathrm{l}$ per ha, the sprayings being carried out on February 27 in the morning, under an overcast sky in calm weather. Since in this second experiment one of the strips was accidentally sprayed together with the rest of the rye fjeld, only two replicates were left.

Nitrogen was applied as ammonium nitrate limestone $(23 \%)$ in the afternoon after the sprayings. In the $1959 / 60$ experiment $0,35,70$ and $110 \mathrm{~kg} \mathrm{~N}$ per ha were given, in the $1960 / 61$ experiment $0,40,80$ and $120 \mathrm{~kg} \mathrm{~N}$ per ha.

In both experiments the plants were expanding their fourth leaf at the time of treatment. No mortality of plants could be detected. In late spring all plots were scuffled to exclude weed competition.

The size of the individual plots, $12.5 \times 4 \mathrm{~m}^{2}$, allowed for a net yield area of $9 \times 3 \mathrm{~m}^{2}$ and for a strip for plant analysis of $2 \times 3 \mathrm{~m}^{2}$, leaving margins of $0.5 \mathrm{~m}$. 
In the $1959 / 60$ experiment the numbers of leaves and tillers were counted on March 2 and 17. On April 4 these measurements were extended to dryweight determinations on samples of aerial parts of 30 plants per plot: drying occurred at $105^{\circ} \mathrm{C}$ overnight. On May 4, 12 and 13, and on July 5, chlorophyll determinations of leaf blades, stalks and ears were made according to Bruinsma ${ }^{3}$. Size and weight of these organs were measured at the same time.

In the second experiment, performed in 1960/'61, the development of the young ear primordium was followed after the method described by Bruinsma and Swarti9. Twice, on May 31 and June 19, samples of aerial parts of plants on $1.59 \mathrm{sq}$. $\mathrm{m}$ of soil area per plot were gathered for determinations of fresh and dry weights and total nitrogen content. Chlorophyll determinations of leaf blades, stalks and ears were made on samples, collected on May 16 and June 13. On the former date, ears were also sampled in order to count the numbers of flowers per ear.

A heat wave on July 2,1961, induced accelerated ripening in the second experiment; afterwards, driving rains caused lodging at the higher nitrogen levels. For these reasons. the average weight per grain in the second experiment was lower than that in the first one: 23.5 and $27.0 \mathrm{mg}$ respectively.

In 1960 the rye was cut and sheaved on July 25 and 26 and in 1961 on July 27 . From each plot, 5 rows of $1 \mathrm{~m}$ length were gathered separately as a sample for yield analyses. The number of ears per sample was counted and in the 1960/'61 experiment the number and position of blind spikelets per ear also. By substraction of the total number of basal and medium blind spikelets and grains per ear from the total number of flowers per ear, as counted on May 16, the number of blind top spikelets per ear was found. After threshing the sample the grain was weighed and the average weight of 100 grains was determined 5 tines per plot. From these figures, the numbers of kernels per ear were calculated.

The sheaves on the field were threshed on August 5 and 7 in the two experiments respectively. The grain weight was afterwards corrected for the weight of the samples. The moisture content of the grains was determined.

\section{RESULTS}

In order to test the fertilizing effect of the nitrogen present in the DNOC spray, in addition to the untreated and DNOC-sprayed plots other plots were sprayed with either urea, containing the same amount of nitrogen, or with DNOC plus urea. Since in neither of the experiments did this little quantity of urea have any effect on growth, development or yield, it can be concluded that DNOC does not act by means of its own nitrogen content. This result is in accordance with similar observations made by Riepma ${ }^{17}$.

Growth and development of the crop showed a similar course 
in the two experiments, a common picture emerging from the two sets of data. This picture, moreover, coincides with the results of a detailed inveștigation into the effects of a DNOC spray on growth, development and yield of winter rye made in another experiment 4. In brief, that experiment showed that after the spray vegetative growth was at first retarded, but that later the treated plants recovered and surpassed the control plants. The stronger vegetative growth was accompanied by prolonged and, therefore, fuller generative development and delayed ripening, resulting in a yield increase of 10 per cent. This experiment will be referred to as the seed-rate experiment.

\section{Vegetative growth and development}

In the present experiments, countings of leaf and tiller numbers revealed that there was no growth retardation after spraying, but that on the other hand the DNOC-treated plants had generally two dead leaves shortly after spraying, as against only one on plants in the control plots. On April 4, 1960, the mear dry weight of the aerial parts of sprayed plants was lower than that of the aerial parts of untreated plants at all nitrogen levels, by an average

TABLE 1

\begin{tabular}{|c|c|c|c|}
\hline \multicolumn{4}{|c|}{ Effect of nitrogen fertilizing on the tillering stage } \\
Average values per plant from samples of 120 plants, collected on April 4, 1960 \\
\hline \begin{tabular}{c|c|c|c|} 
Nitrogen appli- & Number of leaves & Number of tillers & $\begin{array}{c}\text { Aerial parts, } \\
\text { mg dry weight }\end{array}$ \\
cation kg N/ha & & 3.5 & 159 \\
\hline 0 & 11.7 & 4.2 & 184 \\
35 & 13.1 & 4.6 & 204 \\
70 & 14.1 & 4.7 & 226 \\
110 & 15.1 & & \\
\hline
\end{tabular}
\end{tabular}

11 per cent. At that date also, nitrogen deficiency was already clearly apparent and all plots without nitrogen had turned yellowish. Table 1 shows, however, that on the plots with $35 \mathrm{~kg}$ and $70 \mathrm{~kg}$ $\mathrm{N}$ per ha nitrogen deficiency was also hampering growth and development. By May 5, 1960, the plants on the DNOC-sprayed plots had made up their arrears, their fresh and dry weights equalling those of the control plants.

More extensive plant analyses were carried out in the second experiment on samples of aerial parts collected on May 31 and June 
19, 1961 (Table 2). At all nitrogen levels the DNOC-treated plants surpassed the untreated ones in fresh and dry weights and in nitrogen content. With one exception, the average relative deviations are significant $(P$ is the chance that as large or larger differences

TABLE 2

\begin{tabular}{|c|c|c|c|c|}
\hline \multicolumn{5}{|c|}{$\begin{array}{l}\text { Effect of the DNOC spray on growth and development at about flowering } \\
\text { Mean values of } 16 \text { samples of aerial parts of plants from DNOC-treated plots, } \\
\text { expressed as percentages of the average values obtained from the control plots, } \\
\text { both over all nitrogen levels }\end{array}$} \\
\hline \multirow[t]{2}{*}{ 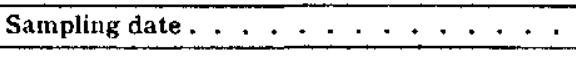 } & \multicolumn{2}{|c|}{ May 31,1961} & \multicolumn{2}{|c|}{ June 19,1961} \\
\hline & & $P$ & & $P$ \\
\hline Fresh weight, per sq. m. . . . . . . & 113 & 0.01 & 109 & 0.20 \\
\hline Dry weight, on a fresh wt. basis . & 97 & 0.01 & 98 & 0.05 \\
\hline Nitrogen content, on a dry wt. basis . . . . & 106 & 0.05 & 107 & 0.05 \\
\hline
\end{tabular}

would also occur under the hypothesis that spraying has no effect at all). The figures equal those obtained in the seed-rate experiment ${ }^{4}$, in which the slightly decreased dry-weight percentage and the increased nitrogen content were interpreted as indicating a somewhat younger condition of the crop, growth rate being increased and rate of development retarded. In support of this view, extensive

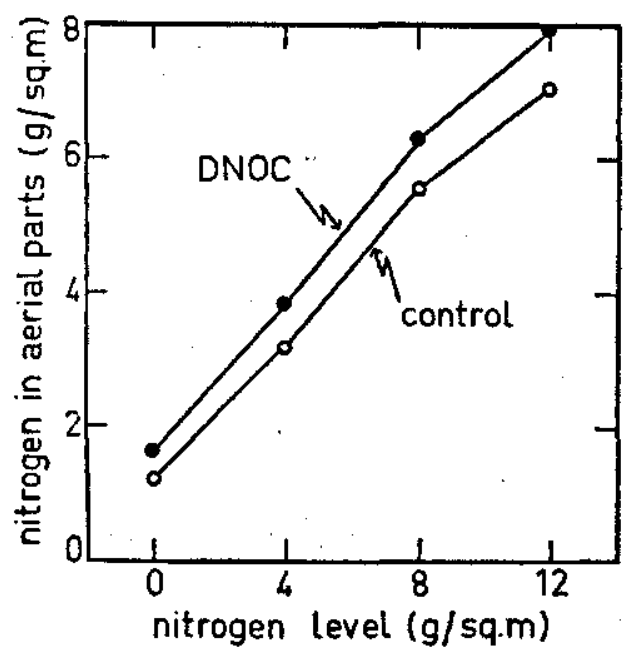

Fig. 1. Effect of the DNOC-spray on nitrogen uptake at different nitrogen levels

Average values of samples of aerial parts from $1.5 \mathrm{sq} . \mathrm{m}$ soil area, collected on May 31, 1961. 
measurements in that experiment showed heading, flowering, and ripening to be delayed for some days. In the present experiments, however, the distance separating field and laboratory precluded such detailed observations.

The amounts of total nitrogen present in the aerial parts at flowering are shown in Figure 1. The plants on the DNOC-sprayed plots always contained more nitrogen, the average difference being $0.66 \mathrm{~g}$ per sq.m. The amount of nitrogen brought into the soil by the DNOC-spray was at most $71 \mathrm{mg}$ per sq.m, of which small quantity only a fraction is found again in the aerial plant parts, as is shown by a comparison of the nitrogen contents of the aerial parts on untreated plots and those which received urea containing an amount of nitrogen equal to that present in the DNOC spray. The aerial parts from the latter plots contained, on an average, $4.18 \mathrm{~g} \mathrm{~N}$ per sq. $\mathrm{m}$, compared with a mean value of $4.15 \mathrm{~g} \mathrm{~N}$ per sq. $m$ from the untreated plots. The extra nitrogen in the DNOCsprayed plants is, therefore, largely derived from other sources than the spraying liquid.

TABLE 3

\begin{tabular}{|}
\hline \multicolumn{3}{|c|}{ The chlorophyll content of the penultimate leaf blade } \\
\hline \multicolumn{3}{|c|}{$\begin{array}{c}\text { Average values of } 6 \text { and } 12 \text { samples of } 15 \text { leaf } \\
\text { blades from nitrogen and DNOC plots respectively }\end{array}$} \\
\hline Treatment & $\mathrm{kg} / \mathrm{ha}$ & \multicolumn{2}{|c|}{ Chlorophyll per leaf, $\mu \mathrm{g}$} \\
\cline { 3 - 5 } & & May 4, 1960 & May 23, 1960 \\
\hline Nitrogen & 0 & 65 & 82 \\
& 35 & 102 & 130 \\
& 70 & 134 & 196 \\
& 110 & 172 & 194 \\
DNOC & 0 & 111 & 140 \\
& 4 & 126 & 161 \\
\hline
\end{tabular}

The stronger vegetative growth on DNOC-sprayed plots was also apparent from chlorophyll determinations. The effects of nitrogen fertilizing and DNOC spraying on the chlorophyll content of culm leaves are shown in Table 3 for the 1959/'60 experiment and in Fig. 2 for the 1960/'61 experiment. Both treatments enhanced the chlorophyll content of the culm blades, but by an increase in blade area rather than by a rise in chlorophyll concentration. Nevertheless, in the field differences in colour between the various nitro- 


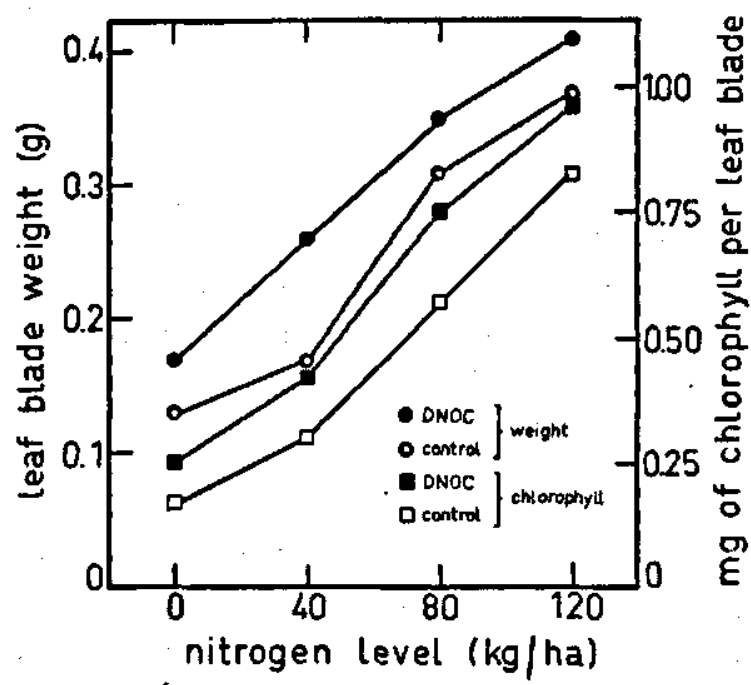

Fig. 2. Effect of the DNOC-spray on weight and chlorophyll content of the penultimate leaf blade at different nitrogen levels

Average values from four determinations on samples of 15 leaves, collected on May 16, 1961.

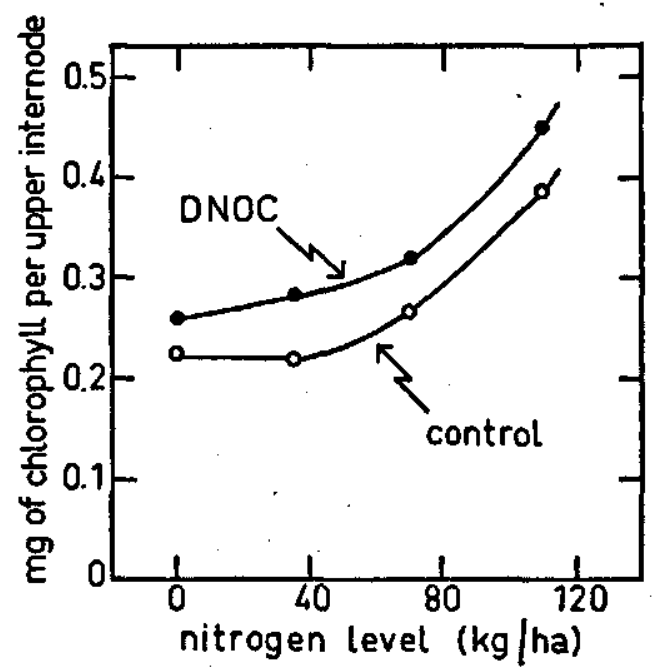

Fig. 3. Effect of the DNOC-spray on the chlorophyll content of the upper internode during ripening at different nitrogen levels

Average values from two determinations on samples of 45 upper internodes, collected on July 5, 1960. 
gen and DNOC treatments were appreciable. On the DNOC-treated plots, leaf sheaths and ears contained also more chlorophyll than did those on the control plots.

Both nitrogen fertilizing and DNOC spraying delayed chlorophyll breakdown at the end of the vegetation period. During ripening, chlorophyll persists longest in the uppermost internode. Fig. 3 shows that at that time the chlorophyll content of this last remaining photo-synthesizing organ depended largely on the nitrogen and DNOC treatments applied during February or March.

\section{Generative growth and development}

In order to examine whether the growth retardation which occurred after spraying was accompanied by a lag in generative development, plant samples were collected on April, 11, 1961, to determine the stage of development of the ear primordia of the main axis. In making the ratings a scale of numbers was used corresponding to the number of days required by spring rye to reach that stage of development under certain standard conditions ${ }^{4}$. The results are given in Table 4.

TABLE 4

\begin{tabular}{|c|c|c|c|}
\hline \multicolumn{3}{|c|}{$\begin{array}{c}\text { Development of ear primordia as at April 11, } 1961 \\
\text { Mean values of } 30 \text { to } 50 \text { ratings according to } \\
\text { a refined scale after Hä nsel 11 }\end{array}$} \\
\hline \multirow{3}{*}{ Nitrogen, kg/ha } & \multicolumn{3}{|c|}{ Developmental stage in standard } \\
& \multicolumn{3}{|c|}{ days } \\
\cline { 2 - 4 } & - DNOC & + DNOC & Difference \\
\hline 0 & 32.9 & 32.5 & -0.4 \\
40 & 35.1 & 34.4 & -0.7 \\
80 & 33.6 & 32.7 & -0.9 \\
120 & 33.8 & 33.5 & -0.3 \\
Average & 33.9 & 33.3 & -0.6 \\
\hline
\end{tabular}

In general, in the flowers of the first order in the middle of the ear, anthers were already differentiated and the lemma had started to grow out. The effect of nitrogen nutrition on the differentiation rate is not clear. The DNOC spray, however, caused a delay of about half a day at all nitrogen levels. Although no similar retarding effect on ear primordium differentiation could be established in the seed-rate experiment 4 , the production of an extra leaf on the culm and the retardation of heading and ripening observed in that 
experiment, point to a similar occurrence there. As has already been mentioned, distance to the field plots in the present experiments prevented detailed observations regarding delays during the later stages of generative development, e.g. about flowering.

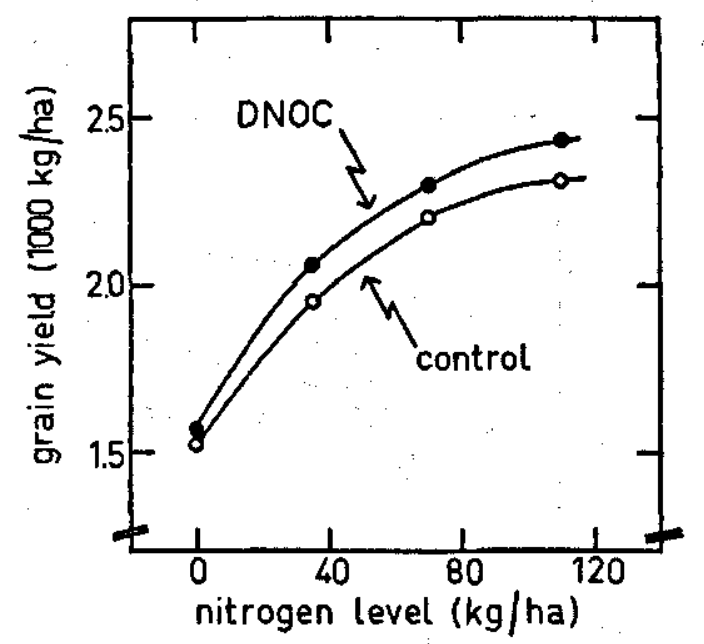

Fig. 4. Grain yield in the $1959 / 260$ experiment.

Average values from 6 determinations of yield per 27 sq. m soil area.

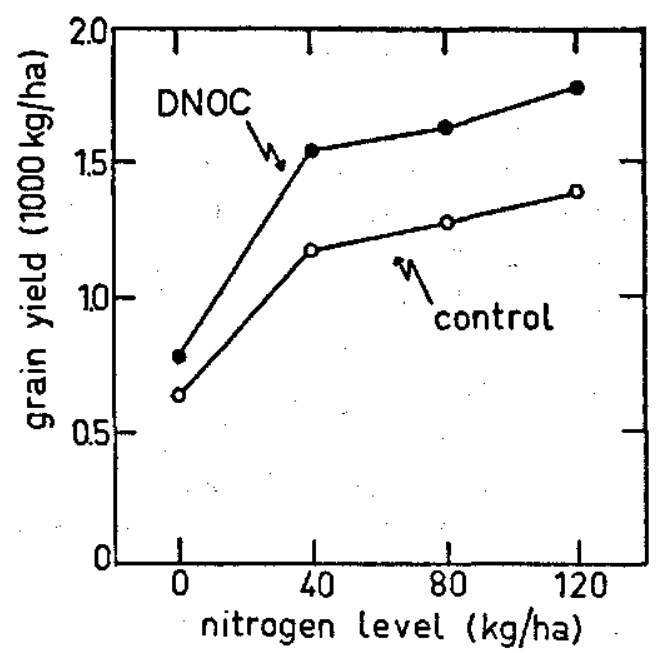

Fig. 5. Grain yield in the 1960/'61 experiment.

Average values from 4 determinations of yield per 27 sq. $\mathrm{m}$ soil area. 


\section{Yield analysis}

The effects of DNOC treatment and of nitrogen fertilizing on grain yield corresponded qualitatively in the two experiments, although there was a marked difference in the magnitude of the DNOC effect. The grain yields, given in Figures 4 and 5, rose with increasing nitrogen fertilizing and were always higher on the DNOCtreated plots than on the corresponding control plots. This does

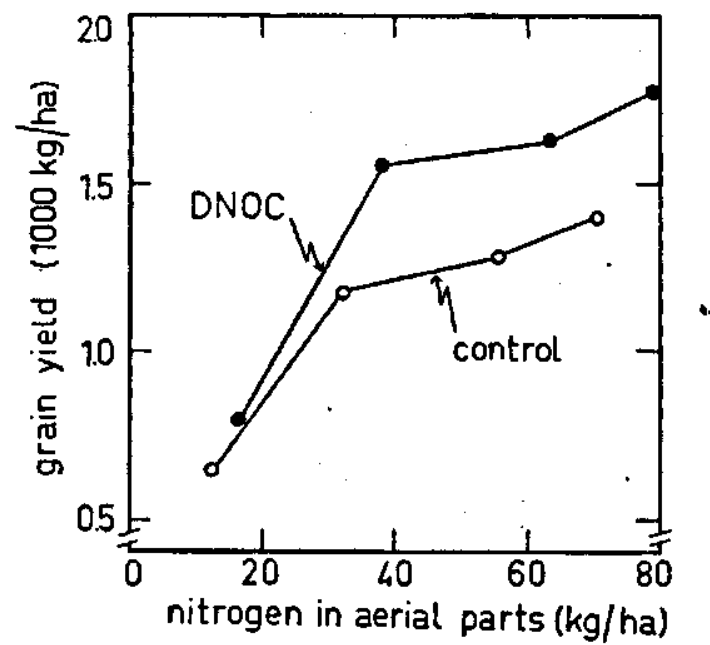

Fig. 6. Effect of nitrogen uptake and DNOC treatment on yield.

The yield values from Figure 5 are here plotted against the values for nitrogen uptake from Figure 2.

not mean, however, that DNOC acts as a nitrogen supply only. If that were true, the strongest effect of the DNOC treatment would be expected where least nitrogen was applied, and with increasing amounts of nitrogen the DNOC effect should diminish until, ultimately, it vanished at nitrogen saturation. On the contrary, however, in both experiments the yield-increasing effect of the DNOC spray is least when no nitrogen is applied, DNOC apparently acting synergistically with nitrogen rather than replacing it. In both figures the curves diverge at higher nitrogen applications and it is highly improbable that they will ever join again. Moreover, from the 1960/'61 experiment not only data about the fertilizing but also about the uptake of nitrogen are available. Here again, if yield is plotted, as in Fig. 6, against the amount of nitrogen present in the 
aerial parts instead of against the amount added to the soil, the two curves will not coincide or meet. This still holds even after corrections for a higher ear density and prolonged filling of the grains on the DNOC-treated plots, as is shown in Fig. 7, in which the number of grains per ear instead of grain weight is plotted against the amount of nitrogen per culm instead of per unit of soil area. The DNOC treatment cannot, therefore, be considered as a mere nitrogen application.

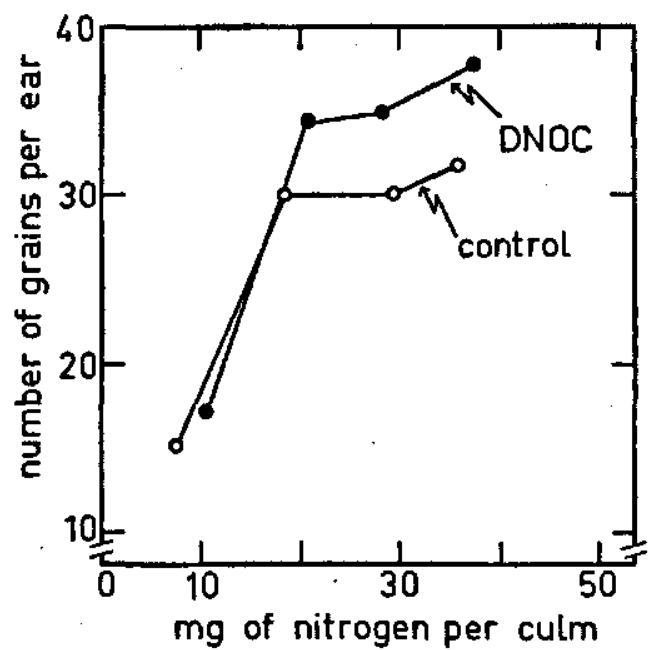

Fig. 7. Effect of nitrogen content per culm and DNOC treatment on the number of kernels per ear.

The values from Figure 6, converted according to the data of the yield analysis in Table 5 .

The effect of the DNOC-spray on the various components of yield is given in Table 5 .

In the 1959/'60 experiments the average effect of the spray on yield was only about 5 per cent, which is rather low, but yet highly significant. Discrepancies between the yields actually found and those calculated from the field analysis data, however, render the value of this analysis questionable. In this experiment, ear density appears to be unaffected by the spray, which is contrary to the findings of the 1960/'61 experiment and elsewhere 4 . The increase in number of grains per ear is not as consistent as the enhancement of weight per grain. The latter finding is remarkable, since a highly 
significant $(P<1 \%)$ decrease in grain weight occurs at higher nitrogen fertilizings. Applications of DNOC and of nitrogen thus apparently affect the weight per grain in opposite directions.

TABLE 5

\begin{tabular}{|c|c|c|c|c|c|c|}
\hline \multicolumn{7}{|c|}{$\begin{array}{l}\text { Analysis of the grain yields } \\
\text { Average values over the four nitrogen levels }\end{array}$} \\
\hline Experiment & Treatments & $\begin{array}{c}\text { Ear } \\
\text { density } \times \\
10^{9} / \mathrm{ha}\end{array}$ & $\begin{array}{c}\text { Number } \\
\text { of } \\
\text { grains/ear }\end{array}$ & $\begin{array}{c}\text { Grain } \\
\text { weight } \\
\mathrm{mg}\end{array}$ & $\begin{array}{l}\text { Grain yield } \\
=\begin{array}{l}\text { metric } \\
\text { tons/ha }\end{array}\end{array}$ & $\begin{array}{c}\text { Actual yield } \\
\text { metric } \\
\text { tons/ha }\end{array}$ \\
\hline $1959 / 60$ & $\begin{array}{c}-\mathrm{DNOC} \\
+\mathrm{DNOC} \\
\text { difference } \\
\text { p<... }\end{array}$ & $\begin{array}{r}2.41 \\
2.39 \\
-1 \%\end{array}$ & $\begin{array}{l}27.5 \\
29.5 \\
+7 \% \\
0.10\end{array}$ & $\begin{array}{l}26.4 \\
27.5 \\
+4 \% \\
0.05\end{array}$ & $\begin{array}{l}1.75 \\
1.94 \\
- \\
0.01\end{array}$ & $\begin{array}{c}1.95 \\
2.04 \\
+5 \% \\
0.01\end{array}$ \\
\hline $1960 / .61$ & $\begin{array}{l}- \text { DNOC } \\
+ \text { DNOC } \\
\text { difference } \\
\mathbf{p}<\ldots\end{array}$ & $\begin{array}{l}1.80 \\
1.95 \\
+8 \% \\
0.15\end{array}$ & $\begin{array}{c}26.7 \\
31.0 \\
+16 \% \\
0.01\end{array}$ & $\begin{array}{l}22.8 \\
24.2 \\
+6 \% \\
0.05\end{array}$ & $\begin{array}{l}1.10 \\
1.46 \\
0.01\end{array}$ & $\begin{array}{c}1.12 \\
1.44 \\
+28 \% \\
0.01\end{array}$ \\
\hline
\end{tabular}

The yield analysis of the 1960/'61 experiment differs from the former in that the average $\mathrm{DNOC}$ effect on yield actually measured is exceptionally high, viz 28 per cent. This strong effect might be partly the result of the heat wave on July 2, 1961, which caused a premature termination of ripening. The less ripened plants on the DNOC-treated plots might have survived a little longer and thereby reached a somewhat higher weight per grain. However, since this difference in grain weight is only 6 per cent, the heat wave alone cannot count for the magnitude of the DNOC effect. It seems reasonable to attribute the yield increase to the larger photosynthetic apparatus of the culms as well.

The agreement between calculated and measured yields in this experiment enhances the reliability of the analysis. Ear density, number of grains per ear and weight per grain are all increased on the DNOC-sprayed plots. From Fig. 8, showing the effect of the spray on ear density at the four nitrogen levels, it appears again that this effect increases as more nitrogen is applied, demonstrating that the treatment does not merely replace a nitrogen supply. This becomes even more evident from Fig. 9, since the DNOC spray not only has no enhancing effect on grain weight in the absence of nitrogen fertilizing but also, in accordance with the 1959/'60 experiment, affects the weight per grain in a direction opposite to that of nitrogen. 


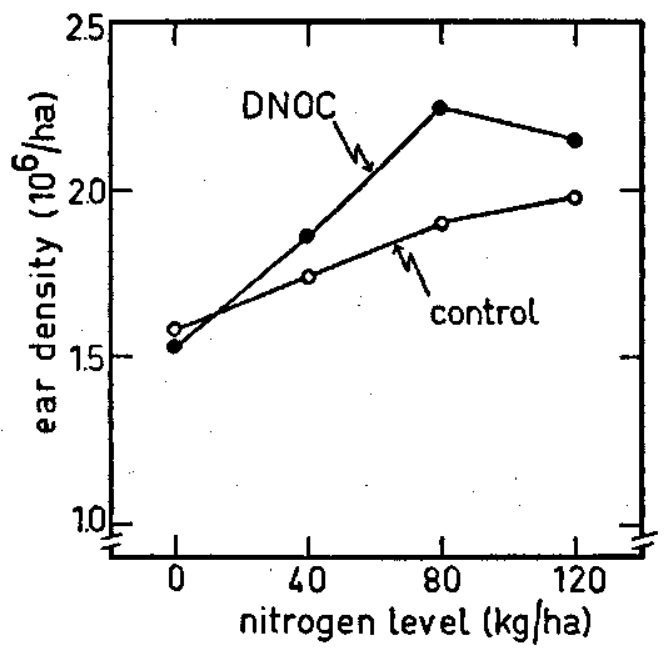

Fig. 8. Effect of the DNOC-spray on ear density at different nitrogen levels (experiment 1960/'61).

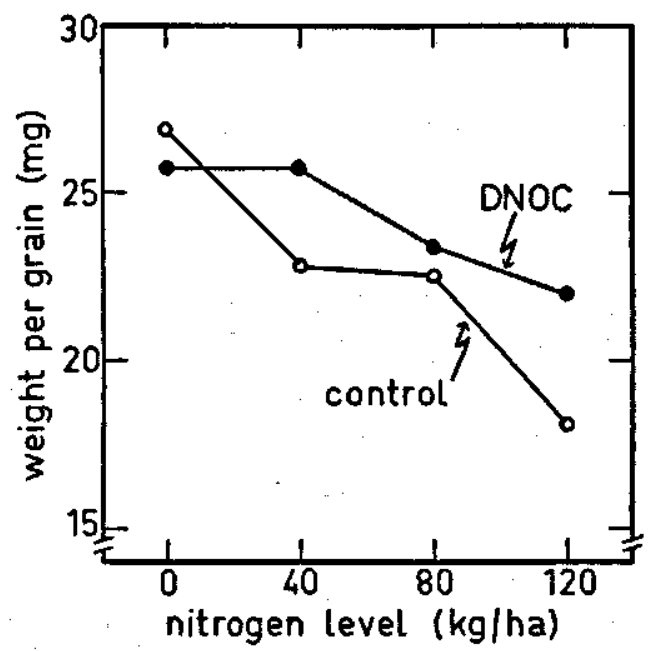

Fig. 9. Effect of the DNOC spray on grain weight at different nitrogen levels (experiment 1960/'61).

The strongest effect of the DNOC treatment appears in the increased number of grains per ear. This number is far smaller than the number of flowers per ear determined earlier, as Table 6 shows. With serious nitrogen deficiency only about a quarter of all flowers developed into grains, while on the plots where nitrogen was applied 
about half of the flowers produced grains. In the middle of the ear few flowers failed to set, most failures occurring at the top and at the base of the ear where the flowers were formed last and did not

TABLE 6

\begin{tabular}{|c|c|c|c|c|c|c|c|}
\hline \multicolumn{8}{|c|}{ Numbers of flowers, grains and blind spikelets per ear } \\
\hline \multirow[b]{2}{*}{$\begin{array}{l}\text { Nitrogen } \\
\text { kg/ha }\end{array}$} & \multirow[b]{2}{*}{ DNOC } & \multirow[b]{2}{*}{$\begin{array}{l}\text { Number of flowers } \\
\text { per ear }(16.5 . ' 61)\end{array}$} & \multicolumn{2}{|c|}{ Number of grains per ear } & \multicolumn{3}{|c|}{ Number of blind spikelets per ear } \\
\hline & & & $\begin{array}{l}\text { absolute } \\
\text { number }\end{array}$ & $\begin{array}{c}\text { as } \% \text { of } \\
\text { flower number }\end{array}$ & at the top & in the middle & $\begin{array}{l}\text { at the } \\
\text { base }\end{array}$ \\
\hline & $\overline{+}$ & 56 & $\begin{array}{ll}15 & \\
& 17\end{array}$ & 27 & 24 & 2 & ${ }_{17}^{15}$ \\
\hline 40 & $\overline{+}$ & 69 & $\begin{array}{ll}30 & \\
& \end{array}$ & 46 & ${ }^{19} 18$ & 2 & 14 \\
\hline 80 & + & 70 & 30 & 43 & 17 & 2 & $21 \quad 18$ \\
\hline 120 & - & 74 & 32 & 43 & 18 & 3 & $\begin{array}{ll}21 & \\
& 17\end{array}$ \\
\hline Average & - & 66 & 31 & 45 & 18 & 2 & $\begin{array}{ll}18 & \\
& 17\end{array}$ \\
\hline & $P$ & $<0.10$ & $<0.01$ & & $<0.10$ & & \\
\hline
\end{tabular}

develop fully. In the DNOC-treated plots somewhat more flowers appeared to be produced per ear, of which, in addition, a slightly larger proportion turned out to be fertile. This was also established in the seed-rate experiment 4.

\section{DISCUSSION}

The present investigation was carried out to answer the question to what extent the effects of a DNOC-spray on growth, development and yield of winter rye are due to the nitrogen supply caused by that spray. The reactions of the crop to the spray do in fact correspond in several respects with those obtainable by nitrogen fertilizing at the same stage of development. Both treatments stimulate vegetative growth and production of photosynthesizing area (Fig. 2, Table 3). Both retard chlorophyll breakdown at ripening (Fig. 3) and enhance yield by increasing both ear density (Fig. 8) and the number 
of flowers and grains per ear (Table 6). In other respects, however, discrepancies between the effects of simultaneous DNOC and nitrogen applications become apparent.

Nitrogen fertilizing immediately promotes growth (Table 1), whereas a DNOC spray is initially followed by a growth retardation which is not overcome until two months later.

Secondly, although the DNOC spray augments the effect of nitrogen fertilizing in several cases, it does not do so at the lowest nitrogen level but, on the contrary, does so most significantly when nitrogen is applied even in large amounts. This appears from data on total yield (Fig. 4 and 5), ear density (Fig. 8) and number of grains per ear (Table 6, Fig. 7). This demonstrates a synergistic rather than a replacing action by the DNOC spray with regard to nitrogen fertilizing. Moreover, if the spray only replaced nitrogen then the spray-induced enhancements should fall away when calculated on a basis of nitrogen uptake instead of nitrogen fertilizing, since on this basis the extra nitrogen from the spray would then be taken into account. Fig. 7 clearly shows, however, that curves plotted in this way still diverge.

Finally, in one significant respect the influences of the two treatments were found to be opposed. Nitrogen fertilizing led to a higher density of ears, each of which contained a larger number of grains, but the weight per grain decreased. In the case of DNOC treatment, however, the enhancement of ear density and of number of grains per ear was accompanied by rising grain weight (Fig. 9). It must be concluded, therefore, that the DNOC spray affects rye plants in some way other than by merely substituting for a simultaneous nitrogen supply.

In analyzing which components of yield are enhanced by the DNOC treatment, it is found that they probably all come into play. The rise in ear density was absent in the 1959/'60 experiment and hardly significant in the 1960/'61 experiment, but has been established elsewhere 4. According to Pollmer 14, weather conditions strongly influence shooting in cereals, thus inducing considerable variability. Since shooting begins before the plants on the DNOC-treated plots overtake those on the control plots, an eventual improved ear density might be the result of a slight retardation of generative development on the DNOC-treated plots (Table 4), enabling more tillers to reach the required size before termination of the shooting period.

A larger and more significant effect than that on ear numbers is found on 
ear weights. Ears from DNOC-treated plots contained heavier and, eśpecially, more grains than did those from the control plots. It is generally recognised that the degree of ear filling, and notably the number of grains, is mainly a matter of nitrogen nutrition. The number of spikelet primordia differentiating in the young spike in March and April depends not only on day length, but also on the availability of nitrogen ${ }^{10}$. Eichinger ${ }^{9}$ ascribes the abortion of top spikelets in April and May, and Pollmer 14 the reduction in the number of basal spikelets at about the time of heading, to nitrogen deficiency at that time. According to Coïc 5, nitrogen manuring at about heading augments both number and weight of grains per ear. Nevertheless, as is evident from the present 1960/'61 experiment the effects of the DNOC spray on the number and weight of grains per ear cannot be ascribed to, the absolute amount of nitrogen present in the aerial parts at the time of optimum development (Fig. 7). It must be admitted, however, that in the seed-rate experiment 4 the DNOC-induced increase in grain weight per ear disappeared if these weights were plotted against the nitrogen content of the culms. In some cases, apparently, DNOC treatment indeed simulates nitrogen fertilizing.

These contradictions can be resolved by tracing the origin of the extra nitrogen in the aerial parts of plants on DNOC-sprayed plots, as shown in Fig. 1. If the possibility is disregarded that this nitrogen is withdrawn from the root system without being replenished from the soil, then the higher nitrogen content also in fact stands for an increased nitrogen uptake. This increase in nitrogen uptake is far too large to be ascribed simply to the amount of nitrogen brought into the soil by the DNOC spray itself: an equal amount of nitrogen in the form of urea enhanced the mean nitrogen content of the aerial parts by only $0.03 \mathrm{~g}$ per sq. $\mathrm{m}$, whereas the average rise due to the DNOC spray amounted to $0.66 \mathrm{~g}$ per sq. $\mathrm{m}$.

Nor can the extra nitrogen be entirely derived from soil micro-organisms killed by the spray, since this killing must have been equal at all four nitrogen levels (the fertilizing being applied after the spray so that at spraying the same microflora and microfauna occurred throughout the experiment), whereas the effects of the spray were mostly small on the unfertilized plots and larger on the fertilized ones. In fact, the extra nitrogen uptake amounted to $0.40 \mathrm{~g}, 0.60 \mathrm{~g}, 0.70 \mathrm{~g}$, and $0.95 \mathrm{~g}$ per sq. $\mathrm{m}$ in the $0,40,80$, and $120 \mathrm{~kg}$ per ha treatments respectively (Fig. 1).

If then the possibility is ruled out that the extra nitrogen in the aerial parts on DNOC-treated plots originates wholly from the spray itself and from nitrogen liberated in the soil by the toxic action of the spray, it must be concluded that DNOC shifts the competition between crop and soil microorganisms for the available nitrogen in favour of the former. In this respect, one is inclined to suggest that the bacteriostatic action of DNOC ${ }^{12}$, which for some time prevents multiplication of many soil micro-organisms on nitrogen-fertilized plots, accounts for the synergistic action of DNOC spraying and nitrogen fertilizing. The heavier the nitrogen application, the more of it remains available for the crop as long as microbial expansion is prevented by $\mathrm{DNOC}$. This possibility requires that the effect of the spray can be imi- 
tated by applying more nitrogen. It has been shown above, however, that nitrogen cannot replace DNOC (Fig. 7) and, moreover, can induce in one respect an opposite effect (Fig. 9).

For these reasons, it is difficult to accept that the extra nitrogen uptake after the DNOC spray results exclusively from factors outside the plant, such as amount of available nitrogen and competitive power of soil microbes. This leads to the conclusion that the uptake capacity of the crop itself is enlarged by the spray, which can be achieved in several ways. One is that the spray kills harmfull soil organisms, e.g. parasitic nematodes. Diminution of populations of such noxious organisms allows for a better development of the root system and thus for increased nitrogen uptake.

Other possibilities arise from the leaf-damaging action of the DNOC spray, which may have various consequences. First, growth and development of the whole plant might be retarded, to recover again somewhat later in the season when better climatic conditions prevail. It is hard to understand, however, how this could contribute to an increased nitrogen uptake. Second, a reduction in the amount of leaves might result in a lowering of the auxin level in the plant. In so far as this level can inhibit root growth, such inhibition may become less, enabling a better development of the root system. Finally, if DNOC damages the leaves to a larger extent than the roots, a lower shoot/root ratio will result. According to Van de Sande Bakhuijzen 18, a little shift in this ratio is sufficient to produce considerable results because it involves changes in the distribution ratio of the plant. Since the leaves assimilate carbon dioxide and the roots take up nitrogen and, moreover, since photosynthesis may well be a limiting factor in the short and often gloomy days of February and March, the lowered shoot/root ratio may well lead to a lowered $\mathrm{C} / \mathrm{N}$ ratio. This lowered $\mathrm{C} / \mathrm{N}$ ratio, of which an indication is to be found in Table 2, is known to be accompanied in cereals by stronger and prolonged vegetative development, as was demonstrated by Borodin 1 and Von Dennfer ${ }^{6}$ for barley, and by Khalil ${ }^{13}$ for wheat. This phenomenon was clearly observed in the seed rate experiment 4 and appears to have occurred again in the present experiment judging by Tables 2 and 3 and Figures 1, 2 and 3. Purvis 15 and Gott, Gregory and Purvis 10 were unable to detect any retarding effect of nitrogen nutrition on developmental rate in winter rye. However, they grew their plants on a small scale and under artificial conditions and rated according to rather rough scales. In all such work, natural variability is quite considerable in relation to the magnitude of the induced effect, and can be eliminated only by minute analyses of large numbers of plants, which only field experiments can supply. The effect is least at the time of differentiation of ear primordia, which was the stage most studied by the authors, and increases to a duration of some days at about flowering, which was estimated in weeks by the authors. Yet even a retardation of only a few days may have a considerable effect on yield. Prolongation of the vegetation period under long day conditions, together with an enlarged root system, allows for a better uptake and distributicn of nitrogen. In the seed-rate experiment 4 conducted on a fairly rich soil, nitrogen uptake could keep up with the stronger vegetative development 
induced by the DNOC spray, and consequently yield per culm proved to be correlated to the nitrogen content of the culm. In the present experiments on rather poor soil, the root system could not keep pace in the long run and thus yield is no longer correlated with nitrogen content. In this case the DNOCtreated plants could profit more from the same amount of nitrogen because duration of uptake and distribution were prolonged. The plots were fertilized early in the season, simultaneously with the DNOC spraying. The plants on unsprayed plots used up their nitrogen in tillering and shooting and had consequently insufficient left for ripening, as is shown by the stimulatory effects of the fertilizer on ear density and grain number and its depressive influence on grain weight. The plants on DNOC-treated plots, on the other hand, could take up additional nitrogen and distribute it during a somewhat longer period, leading to a rise even in grain weight, which can also be achieved by applying a late nitrogen dose 5 .

It can be concluded that the DNOC spraying in winter rye does not act merely as a nitrogen application but rather that it affects growth, development and yield by enabling the crop to make better use of the nitrogen present in plant and soil.

\section{SUMMARY}

Spraying a young cereal crop with the herbicide DNOC enhances yield apart from its weed-eliminating action. This study examined the extent to which this increase is due to the nitrogen-fertilizing effect of the spray. To this end the effects of a spray on growth, nitrogen uptake and yield of winter rye were examined at four nitrogen levels in two field experiments.

Analogous in many respects to nitrogen fertilizing, the DNOC spray stimulated vegetative growth and the production of photosynthesizing area, retarded chlorophyll breakdown at ripening and increased yield by improving both the number of ears and number of grains per ear. It differed, however, in that growth stimulations was preceded by a temporary retardation and also in that the other positive effects were generally strongest not under conditions of nitrogen deficiency but when DNOC was applied together with nitrogen. The thousand-kernel weight was affected in opposite directions by the two treatments. The extra amounts of nitrogen taken up by the DNOCtreated plants could not account for the magnitude of the effects of the spray.

It is argued that the DNOC spray, rather than replacing nitrogen, promotes a better use of it by inducing stronger growth of the root system and a prolongation of the vegetation period. This involves both a larger uptake of nitrogen from the soil and a better distribution of it in the plant. 


\section{ACKNOWLEDGEMENTS}

The ready co-operation of Miss E. Gerritsen and Mr. J. Swart in the experimental part of the work is gratefully acknowledged. The author thanks the members of staff of the I.B.S., Wageningen, especially Dr. W. H. van Dobben and Dr. W. van der $Z$ weep, and the people of the B.G.D., Wageningen, for their helpfullness in many respects; also Mr. M. Keuls and Mr. C. A. Hoveijn for the statistical treatment of data.

Received March 26, 1962

\section{REFERENCES}

1 Borodin, I., The influence of nitrogenous and mineral nutrition on the time of heading in barley and millet under the conditions of different day length. Bull. Appl. Botany Genet. Plant Breeding Leningrad 27, 171-195 (1931).

2 Bruinsma, J., The action of 4,6-dinitro-o-cresol (DNOC) in soil. I. The emergence from cress seed in DNOC-treated soil mixtures. Plant and Soil 12, 249-258 (1960).

3 Bruinsma, J., The effect of pesticides on the chlorophyll content of leaves and stalks. Mededel. Landbouwhogeschool Gent 26, 1513-1522 (1961).

4 Bruinsma, J., The effect of a spray with 4,6-dinitro-o-cresol (DNOC) on growth, development and yield of winter rye (Secale cereale L.). Weed Research 2, 73-89 (1962).

5 Coĩc, Y., Recherches sur le meilleur équilibre entre densité de plantes et fertilisation azotée du blè d'hiver. Ann. Physiol. Végétale 1, 53-58 (1959).

6 Dennfer, D. von, Blühhormon oder Blühhemmung? Neue Gesichtspunkte zur Physiologie der Blütenbildung. Naturwiss. 37, 296-301, 317-321 (1950).

7 Dobben, W. H. van, The influence of spraying with DNOC on the growth of winter rye. Verslag C.I.L.O. (Wageningen) 195.), 133-14t (1956).

8 Dobben, W. H. van, Unpublished data.

9 Eichinger. Die Becinflussung der Länge der Winterroggenähren und der Zahl der Aehrchen durch Düngung und Aussaatzeit. Eine Methode zur Unterscheidung von Winter- und Sommersaatgut. Angew. Botan. 10, 66-79 (1928).

$10 \mathrm{Gott}$, M. B., Gregory, F. G., and Purvis, O. N., Studies in vernalisation of cereals. 13. Photoperiodic control of stages in flowering between initiation and ear formation in vernalised and unvernalised Petkus Winter rye. Ann. Botany N.S. 19, 87-126 (1955).

11 Hansel, H., Vernalisation of winter rye by negative temperatures and the influence of vernalisation upon the lamina leaf length of the first and second leaf in winter rye, spring barley and winterbarley. Ann. Botany N.S. 17, 417-432 (1953).

12 Jensen, H. L. and Petersen, H. I., Decomposition of hormone herbicides by bacteria. Acta Agr. Scand. 2, 215-231 (1952).

$13 \mathrm{Khali1}, \mathrm{M}$. S. H., The interrelation between growth and development of wheat as

- influenced by temperature, light and nitrogen. Mededel. Landbouwhogeschool Wageningen 5(t, (7), 1-73 (1956).

14 Pollmer, G., Lntersuchungen zur Ertragsbildung bei Sommerweizen. Z. Pflanzenzüchtung 37, 231-262 (1957). 
15 Purvis, O. N., An analysis of the influence of temperature during germination on the subsequent development of certain winter cereals and its relation to the effect of length of day. Ann. Botany 48, 919-955 (1934).

16 Riepma, P. Kzn., The importance of DNOC for the grain crops in the Netherlands. Landbouwk. Tijdschr, 65, 334-338 (1953).

17 Riepma, P. Kzn., The reaction of cereals and pulse crops on dinitro's. Mededel. Landbouwhogeschool Gent 19, 451-456 (1954).

18 Sande Bakhuijzen, H. L. van de, Basic principles in the growth of wheat and other agricultural plants. Landbouwk. Tijdschr. 41, 885-900 (1937).

19 Bruinsma, J. and Swart, J., The development of the rye spike until emergence. Acta Botan, Neerl. 11, 411.417 (1962). 